\title{
Modified Robert Jones bandage can not reduce postoperative swelling in enhanced- recovery after primary total knee arthroplasty without intraoperative tourniquet: a randomized controlled trial
}

\author{
Haoda Yu ${ }^{\dagger}$, Haoyang Wang ${ }^{\dagger}$, Kai Zhou, Xiao Rong, Shunyu Yao, Fuxing Pei and Zongke Zhou ${ }^{*}$
}

\begin{abstract}
Background: Compression therapy is commonly used to reduce lower limb swelling and blood loss after knee surgery. This study was performed to investigate whether modified Robert Jones bandage (MRJB) as a postoperative compression therapy is necessary for enhanced-recovery primary total knee arthroplasty without the tourniquet application.
\end{abstract}

Methods: In this prospective randomized controlled trial, 90 patients were grouped into 2 groups randomly. The experimental group received compression therapy with MRJB from toes to thigh for $24 \mathrm{~h}$ and the control group received no compression therapy. Knee swelling, blood loss, range of motion (ROM), pain, patient reported comfort level and complications were recorded.

Results: No significant differences were observed between the two groups when we compared knee swelling. Similarly, no significant difference on postoperative blood loss, pain, ROM, complications was found. However, patients in control group had significantly higher comfort ratings than compression group during the first $24 \mathrm{~h}$.

Conclusions: MRJB is not routinely indicated in enhanced-recovery primary total knee arthroplasty without tourniquet application.

Trial registration: The trial was registered in the Chinese Clinical Trial Registry (ChiCTR-INR-16010177) dated 18th December 2016.

Keywords: Total knee arthroplasty, Swelling, Modified Robert jones bandage, Compression

\section{Background}

Total knee arthroplasty (TKA) is a common and highly successful orthopedic operation to relieve pain and improve knee function in people with end-stage knee osteoarthritis [1]. However, TKA is associated with the high prevalence of postoperative knee swelling, which results in decreased knee-extension strength and impaired functional performance [2]. Knee swelling is due to intra-articular bleeding and peri-articular

\footnotetext{
* Correspondence: zongkezhou@126.com

${ }^{\dagger}$ Haoda Yu and Haoyang Wang contributed equally to this work.

Department of Orthopedics, West China Hospital, Sichuan University,

Chengdu 610041, China
}

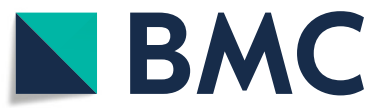

(c) The Author(s). 2018 Open Access This article is distributed under the terms of the Creative Commons Attribution 4.0 International License (http//creativecommons.org/licenses/by/40/) which permits unrestricted use, distribution, and reproduction in any medium, provided you give appropriate credit to the original author(s) and the source, provide a link to the Creative Commons license, and indicate if changes were made. The Creative Commons Public Domain Dedication waiver (http://creativecommons.org/publicdomain/zero/1.0/) applies to the data made available in this article, unless otherwise stated. Modified Robert Jones bandage (MRJB) from toes to mid-thigh is commonly performed in patients who underwent arthroplasty with the hypothesis that it could reduce intra-articular bleeding by providing tamponade effect in the knee and reduce soft tissue edema by increasing intra-tissular pressure, aiding venous return in the lower limb [3, 4]. However, if the bandage is too tight, the excessive external pressure could lead to tissue ischemia by obliterating blood flow to subcutaneous tissue [5]. Compression-related complications including bruises, blisters, peroneal nerve palsy and discomforts 
complaint from patients have been reported by various researchers [6-8].

Recently, the growing trend of quicker recovery following orthopedic procedures has stimulated the development of the techniques focused on reducing post-operative knee swelling. In addition to compression, various postoperative methods including surgery without intraoperative tourniquet use, administration of tranexamic acid (TXA) and corticosteroid medication have been reported to be effective to reduce hemarthrosis and soft tissue edema $[9,10]$, as this multi-modal swelling management could effectively reduce post-operative hidden blood loss and limit inflammation. However, few studies have adequately investigated and demonstrated the benefits of MRJB when applied together with this multi-modal swelling management, resulting in a knowledge gap and inability to determine if MRJB is still necessary for patients undergoing primary TKA in an enhanced recovery after surgery (ERAS) program. Therefore, we conducted this prospective randomized controlled trial (RCT) to evaluate the effect of using MRJB on knee swelling, blood loss, pain, complications and patient-reported knee function after TKA. We hypothesized that MRJB is not necessary when this multi-modal swelling management is utilized in enhanced-recovery after primary total knee arthroplasty.

\section{Methods}

\section{Study design}

This prospective, randomized controlled study was approved by the institutional review board of West China Hospital of Sichuan University (no. 201302009) and registered in the Chinese Clinical Trial Registry (ChiCTR-INR-16010177). All patients, aged 18 years or older, who were scheduled for a primary total knee arthroplasty for end-stage osteoarthritis were eligible for inclusion. Exclusion criteria included simultaneously bilateral total knee arthroplasty or revision case, surgical history of the knee joint, peripheral vascular disease, ankle brachial pressure index, $\mathrm{ABPI}<0.8$, peripheral neuropathy, blood coagulation disorders, history of deep venous thrombosis, $\mathrm{BMI}>35$, knee stiffness characterized as flexion deformity of $\geq 30^{\circ}$. Informed consent was obtained from all participants.

\section{Treatment groups}

Recruited patients were randomly allocated to either the MRJB or the conventional wound dressing group according to a computerized random sequence generator. After wound closure, sequentially numbered, sealed envelopes were opened in the operating room. In the MRJB group, the sterile adhesive wound dressing Cosmopor ${ }^{\circ} \mathrm{E}$ (Paul Hartmann AG, Heidenheim, Germany) was placed over the wound followed by a soft inner layer thick cotton padding Winner (Chengdu Wenjian Likang Medical Products Ltd., Sichuan, China) which was applied from toes to thigh. The outer layer was composed of elastic bandage Coban ${ }^{\text {tm }}$ (3 M Deutschland GmbH, Neuss, Germany). To enhance venous return, more tension was applied distally than proximally (Fig. 1). The MRJB retained for 24 h postoperatively, while the conventional wound dressing group was treated with sterile adhesive wound dressing over the wound only (Fig. 2). The surgeons were blinded to the treatment assignment until wound closure, and data collector were blinded during the entire study.

\section{Surgical procedures}

All TKAs were performed by the same surgical team by using a midline skin incision, a standard medial parapatellar approach, and a measured resection technique. A cemented posterior-stabilized prosthetic total knee prosthesis (PFC, Johnson \& Johnson/DePuy, Warsaw, IN, USA) was used. All of the patients received an intravenous administration of TXA 5 to $10 \mathrm{~min}$ before the skin incision $(20 \mathrm{mg} / \mathrm{kg})$ and 3, $6 \mathrm{~h}$ later $(1 \mathrm{~g})$ along with $1 \mathrm{~g}$ of topical TXA in $50 \mathrm{~mL}$ of normal saline solution. No tourniquet or wound drainage was used in any patient and no blood salvage system was used. Electrocautery and routine hemostasis were performed during the surgery. Surgical time, intraoperative blood loss volume was recorded. All patients had adductor canal block $(20 \mathrm{ml}$ $5 \mathrm{~g} / \mathrm{L}$ ropivacaine and $0.1 \mathrm{mg}$ adrenaline) performed before surgery and periarticular infiltration analgesia (70 $\mathrm{ml} 2.5 \mathrm{~g} / \mathrm{L}$ ropivacaine and $0.1 \mathrm{mg}$ adrenaline) during surgery.

\section{Postoperative care protocol}

After the operation, the patients were transferred to the anesthesia recovery unit, where they remained for $1 \mathrm{~h}$, and then to the bed-ward. A cold pack was used on the surgical site and a single dose of $10 \mathrm{mg}$ intravenous

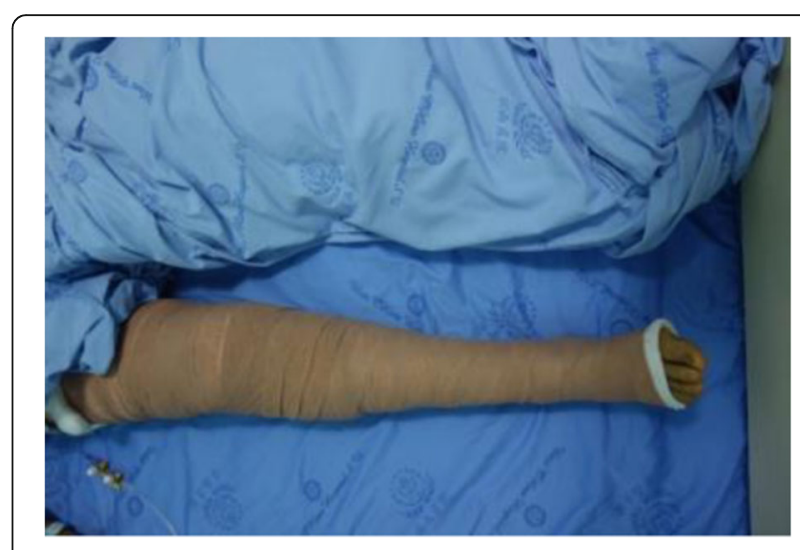

Fig. 1 A MRJB is shown on a patient 


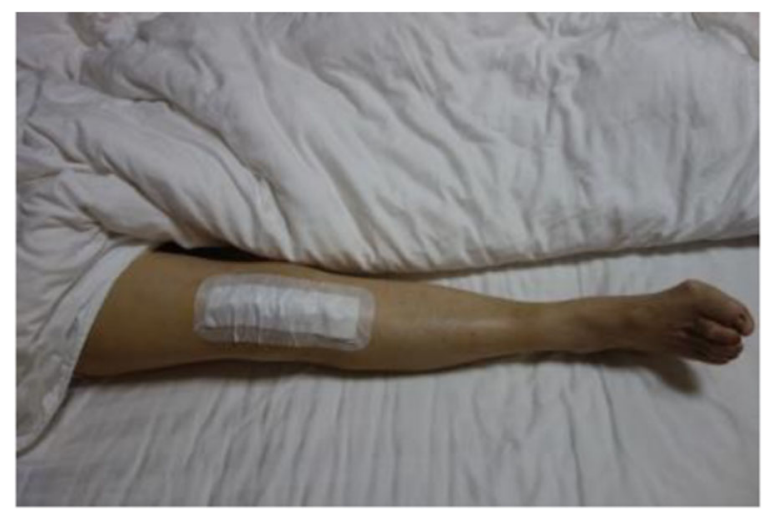

Fig. 2 A conventional wound dressing is shown on a patient

dexamethasone was administered when patients arrived inpatient unit $[9,11]$. Postoperative oral Loxoprofen sodium (Loxonin; $60 \mathrm{mg}$ three times daily) and Pregabalin (Lyrica; $75 \mathrm{mg}$ twice daily) were administered for pain $[12,13]$. A standard venous thromboembolism prophylaxis protocol combined mechanical and chemical prophylaxis was adopted for all patients [9]. An intermittent inflatable lower-extremity pump was used as a routine practice to prevent deep venous thrombosis (DVT) before the patient began walking. Low-molecular-weight heparin (LMWH; Clexane, Sanofi-Aventis, France, 2000 IU) was administered subcutaneously 8 h postoperatively, and a full dose $(0.4 \mathrm{~mL}$ containing $4000 \mathrm{IU})$ was given at 24-h intervals during hospitalization. After discharge, rivaroxaban (10 mg, Xarelto, Bayer, Germany) was administered orally for 10 days if no bleeding events occurred.

Criteria for transfusion included a $\mathrm{Hb}$ level less than $7 \mathrm{~g} / \mathrm{dL}$ or symptomatic anemia (light-headedness, palpitation, or shortness of breath not due to other causes) in a patient with an $\mathrm{Hb}$ level of 7 to $10 \mathrm{~g} / \mathrm{dL}$ [9].

\section{Outcome measurements}

The primary outcome was swelling, which was measured as circumference of superior pole of patella, inferior pole of patella, mid-line of patella, thigh $(10 \mathrm{~cm}$ above superior pole of the patella) and calf $(10 \mathrm{~cm}$ below to inferior pole of the patella) at postoperative day (POD) 1, POD3 and 3 weeks after surgery. The secondary outcomes included range of motion (ROM), hospital for special surgery knee score, visual analog scale (VAS) at rest and at walking, reduction in $\mathrm{Hb}$ concentration, postoperative calculated blood loss, complications and patient satisfaction. The blood volume of each patient was calculated according to a formula published by Nadler et al. that considers patients' weight, height and gender [14, 15]. Complications such as nerve palsy, bruises, blisters were recorded. Doppler ultrasound was used to evaluate for DVT when a patient has any suspicious symptom of
DVT, including severe pain, swelling, tenderness, superficial venous engorgement and Homan's sign. Pulmonary embolism (PE) was diagnosed by clinical symptoms and an enhanced chest computed tomography (CT) scan. All adverse events were recorded during the first 3 weeks after surgery (Fig. 3). All of the patients completed a comfort level questionnaire regarding the feeling of the operated lower limb that asked them to rate their comfort on a 5-point scale ranging from very uncomfortable to very comfortable.

\section{Statistical analysis}

Quantitative data were presented as mean and standard deviation, qualitative data were presented as size number. Differences in continuous variables between the two groups were evaluated using Student's t-test or MannWhitney $U$ test, depending on the distribution characteristics of the data. A chi-square test or Fisher's exact test for difference in proportions was used to estimate differences between groups in categorical variables. The sample size estimate was based on the difference in the primary outcome (i.e., reduction in mean knee circumference) and calculation was performed using $G^{*}$ Power Version 3.1.9.2 (Franz Faul, Uni Kiel, Germany) software with an unpaired $\mathrm{t}$ test of variance design assuming a standard effect size $(\mathrm{d})=0.67$, an alpha level (two-tailed) $=0.05$, and power $=0.90$. We took $2 \mathrm{~cm}$ as clinical minimal relevance in circumference based on a previous study [16], and assumed standard deviation within each group to be $3 \mathrm{~cm}$. Based on the information mentioned above, 39 patients each arm were needed. Allowing for a $15 \%$ loss to follow up, a total of 90 patients were planned to include in this study.

\section{Results}

\section{Patients' demographics}

During recruitment from December 2016 to May 2018, a total of 453 patients scheduled to take a primary

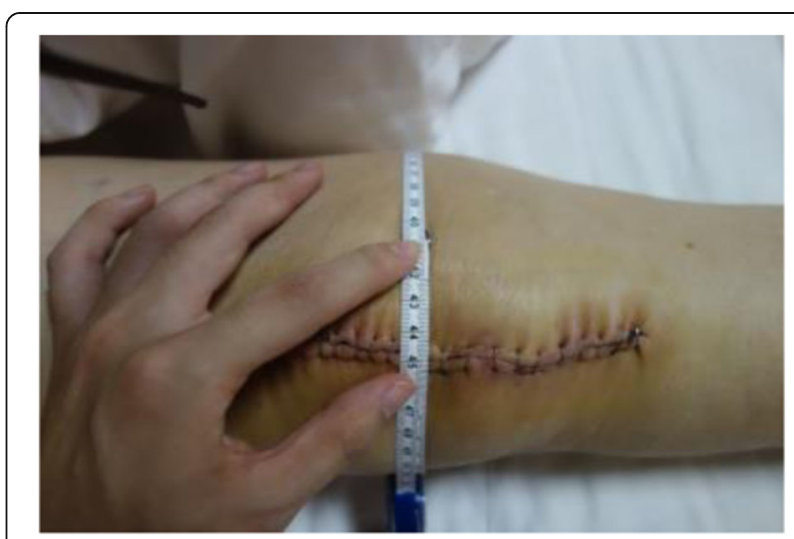

Fig. 3 Measurement of swelling 
unilateral TKA were screened. Of them all, 143 patients were ineligible, 220 declined to participate, and the remaining 90 participants were enrolled. Each group lost 1 patient during follow-up. Baseline demographic data were comparable between the 2 groups (Table 1).

\section{Primary outcome}

No significant differences were observed between the two groups when we compared knee circumference at superior margin of patella, inferior margin of patella, mid-line of patella at any measurement point (Table 2).

\section{Secondary outcome}

No significant differences were observed in the total blood loss between the 2 groups. Similarly, transfusion rate showed no significant difference. As to the postoperative general assessments, no significant difference on Pain, ROM, HSS was found (Table 3). However, patients in control group had significantly higher comfort ratings than the experimental group during the first $24 \mathrm{~h}$ (Table 4). No nerve palsy, PE or DVT was observed in the 2 groups. Superficial skin complications including bruises and blisters also showed no significant difference.

\section{Discussion}

Hidden blood loss and inflammation are believed to be main factors that caused post-operative swelling. Based on this mechanism, various methods have been introduced to reduce post-operative knee swelling.

Table 1 Demographic characteristic of patients

\begin{tabular}{llll}
\hline & Compression group & Control group & $P$ value \\
\hline Age $(\mathrm{yr})$ & $69.32 \pm 8.29$ & $69.11 \pm 8.66$ & 0.91 \\
${ }^{\mathrm{a}}$ Gender (Male/Female) & $10 / 34$ & $10 / 34$ & 1 \\
Height (m) & $1.58 \pm 0.09$ & $1.59 \pm 0.08$ & 0.64 \\
Weight (kg) & $64.39 \pm 9.47$ & $64.67 \pm 10.82$ & 0.90 \\
BMI (kg/m $\left.{ }^{2}\right)$ & $25.80 \pm 2.88$ & $25.60 \pm 3.24$ & 0.76 \\
Circumference (cm) & & & \\
Superior pole of patella & $39.53 \pm 2.91$ & $39.47 \pm 3.64$ & 0.93 \\
Mid-line of patella & $38.31 \pm 2.71$ & $38.13 \pm 3.28$ & 0.78 \\
Inferior pole of patella & $36.31 \pm 2.85$ & $36.18 \pm 3.15$ & 0.83 \\
Thigh & $44.83 \pm 36.59$ & $44.64 \pm 4.30$ & 0.82 \\
Calf & $34.07 \pm 2.43$ & $33.79 \pm 2.52$ & 0.60 \\
Hemoglobin (g/dL) & $132.23 \pm 12.55$ & $134.09 \pm 12.84$ & 0.49 \\
Hematocrit (\%) & $40.25 \pm 3.25$ & $40.11 \pm 3.38$ & 0.85 \\
ROM & $96.55 \pm 14.22$ & $92.91 \pm 14.04$ & 0.23 \\
Pain at walking(VAS) & $6.23 \pm 1.27$ & $6.34 \pm 1.20$ & 0.59 \\
Pain at rest(VAS) & $1.39 \pm 1.71$ & $1.14 \pm 1.49$ & 0.55 \\
\hline BMIbody mass & & & \\
\hline
\end{tabular}

BMI body mass index, ROM range of motion, VAS visual analogue scale a Presented as number and percent, and $P$-values were calculated by chisquare and Fisher exact test
Table 2 Postoperative primary outcomes

\begin{tabular}{|c|c|c|c|}
\hline Variable & Compression group & Control group & $P$ value \\
\hline \multicolumn{4}{|c|}{ Mean circumference $(\mathrm{cm})$} \\
\hline \multicolumn{4}{|c|}{ Superior pole of patella } \\
\hline POD1 & $41.75 \pm 2.90$ & $41.61 \pm 3.46$ & 0.84 \\
\hline POD3 & $42.64 \pm 2.88$ & $42.56 \pm 3.50$ & 0.91 \\
\hline $3 w$ & $40.19 \pm 2.89$ & $40.11 \pm 3.57$ & 0.91 \\
\hline POD1 change & $2.22 \pm 1.01$ & $2.14 \pm 0.86$ & 0.71 \\
\hline POD3 change & $3.10 \pm 1.31$ & $3.08 \pm 1.12$ & 0.95 \\
\hline 3 w change & $0.66 \pm 0.26$ & $0.64 \pm 0.25$ & 0.80 \\
\hline \multicolumn{4}{|l|}{ Mid-line of patella } \\
\hline POD1 & $40.40 \pm 2.66$ & $40.26 \pm 3.28$ & 0.84 \\
\hline POD3 & $41.31 \pm 2.62$ & $41.03 \pm 3.37$ & 0.67 \\
\hline $3 w$ & $38.97 \pm 2.62$ & $38.82 \pm 3.25$ & 0.82 \\
\hline POD1 change & $2.09 \pm 0.96$ & $2.13 \pm 0.93$ & 0.81 \\
\hline POD3 change & $3.00 \pm 1.32$ & $2.90 \pm 1.27$ & 0.73 \\
\hline 3w change & $0.66 \pm 0.31$ & $0.69 \pm 0.26$ & 0.56 \\
\hline \multicolumn{4}{|c|}{ Inferior pole of patella } \\
\hline POD1 & $38.08 \pm 2.71$ & $37.97 \pm 3.22$ & 0.87 \\
\hline POD3 & $38.88 \pm 3.11$ & $38.53 \pm 3.54$ & 0.63 \\
\hline $3 w$ & $36.92 \pm 2.81$ & $36.73 \pm 3.17$ & 0.77 \\
\hline POD1 change & $1.76 \pm 1.14$ & $1.79 \pm 0.98$ & 0.90 \\
\hline POD3 change & $2.57 \pm 1.63$ & $2.35 \pm 1.46$ & 0.52 \\
\hline 3 w change & $0.61 \pm 0.36$ & $0.56 \pm 0.31$ & 0.48 \\
\hline \multicolumn{4}{|l|}{ Thigh } \\
\hline POD1 & $46.23 \pm 3.49$ & $45.90 \pm 4.19$ & 0.68 \\
\hline POD3 & $46.87 \pm 3.68$ & $46.57 \pm 4.22$ & 0.72 \\
\hline $3 w$ & $45.79 \pm 3.46$ & $45.53 \pm 4.14$ & 0.74 \\
\hline POD1 change & $1.40 \pm 0.71$ & $1.26 \pm 0.66$ & 0.35 \\
\hline POD3 change & $2.03 \pm 0.96$ & $1.93 \pm 0.90$ & 0.61 \\
\hline 3w change & $0.96 \pm 0.61$ & $0.89 \pm 0.58$ & 0.58 \\
\hline \multicolumn{4}{|l|}{ Calf } \\
\hline POD1 & $35.20 \pm 2.44$ & $34.95 \pm 2.63$ & 0.65 \\
\hline POD3 & $35.30 \pm 2.52$ & $35.07 \pm 2.67$ & 0.68 \\
\hline $3 w$ & $34.82 \pm 2.39$ & $34.54 \pm 2.46$ & 0.60 \\
\hline POD1 change & $1.12 \pm 0.66$ & $1.16 \pm 0.62$ & 0.83 \\
\hline POD3 change & $1.22 \pm 0.78$ & $1.27 \pm 0.70$ & 0.75 \\
\hline $3 w$ change & $0.74 \pm 0.56$ & $0.75 \pm 0.43$ & 0.95 \\
\hline
\end{tabular}

Tourniquet-induced ischemia could increase fibrinolytic activity and induce local reactive hyperemia, resulting in more hidden blood loss [17]. Thus, abandoning tourniquet could lead to less hidden blood loss and a lower ratio of postoperative knee swelling [9]. Ishida et al. reported that the intra-articular administration of TXA reduced knee swelling by diminishing the hidden blood loss [18]. Furthermore, both TXA and corticosteroid 
Table 3 Postoperative secondary outcomes

\begin{tabular}{|c|c|c|c|}
\hline Variable & $\begin{array}{l}\text { Compression } \\
\text { group }\end{array}$ & $\begin{array}{l}\text { Control } \\
\text { group }\end{array}$ & $P$ value \\
\hline \multicolumn{4}{|l|}{$\begin{array}{l}\text { Postoperative Hb drop } \\
(\mathrm{g} / \mathrm{dL})\end{array}$} \\
\hline POD1 drop & $18.91 \pm 7.68$ & $18.45 \pm 8.17$ & 0.79 \\
\hline POD3 drop & $28.75 \pm 10.01$ & $29.27 \pm 12.21$ & 0.83 \\
\hline \multicolumn{4}{|l|}{$\begin{array}{l}\text { Postoperative blood loss } \\
(\mathrm{mL})\end{array}$} \\
\hline POD1 drop & $252.48 \pm 124.92$ & $250.75 \pm 106.60$ & 0.94 \\
\hline POD3 drop & $529.30 \pm 232.62$ & $558.94 \pm 252.74$ & 0.57 \\
\hline $\begin{array}{l}\text { Intraoperative blood loss } \\
(\mathrm{mL})\end{array}$ & $188.70 \pm 80.33$ & $178.14 \pm 77.65$ & 0.53 \\
\hline \multicolumn{4}{|l|}{ VAS at walking } \\
\hline${ }^{*}$ POD1 & $6.23 \pm 1.89$ & $5.89 \pm 1.62$ & 0.37 \\
\hline *POD3 & $2.16 \pm 0.94$ & $1.98 \pm 0.93$ & 0.46 \\
\hline \multicolumn{4}{|l|}{ VAS at rest } \\
\hline *POD1 & $2.39 \pm 1.91$ & $1.91 \pm 1.60$ & 0.28 \\
\hline *POD3 & $0.39 \pm 0.72$ & $0.41 \pm 0.62$ & 0.59 \\
\hline \multicolumn{4}{|l|}{$\mathrm{ROM}\left({ }^{\circ}\right)$} \\
\hline POD1 & $77.50 \pm 20.00$ & $78.30 \pm 17.39$ & 0.84 \\
\hline POD3 & $99.16 \pm 9.36$ & $97.68 \pm 10.43$ & 0.49 \\
\hline HSS & $80.55 \pm 5.36$ & $79.34 \pm 4.66$ & 0.26 \\
\hline \multicolumn{4}{|l|}{ Complications } \\
\hline${ }^{\dagger} \mathrm{DVT}$ & 0 & 0 & - \\
\hline${ }^{\dagger} \mathrm{PE}$ & 0 & 0 & - \\
\hline${ }^{\dagger}$ Transfusion & 0 & 0 & - \\
\hline${ }^{\dagger}$ Bruises & 1 & 1 & 1 \\
\hline${ }^{\dagger}$ Blisters & 1 & 1 & 1 \\
\hline${ }^{\dagger}$ Nerve palsy & 0 & 0 & - \\
\hline
\end{tabular}

$P O D$ postoperative day, VAS visual analogue scale, $R O M$ range of motion, HSS hospital for special surgery knee score, DVT deep vein thrombosis, $P E$ pulmonary embolism

${ }^{*} P$ values calculated using the Mann-Whitney $U$ test

${ }^{\dagger}$ presented as number and the $P$-values were calculated by chi-square and Fisher exact test

have anti-inflammatory effects which could also contribute to reduction of swelling $[19,20]$. All of the methods mentioned above are now routinely used in our institution for enhanced recovery.

Modified Robert Jones bandage, which was introduced by Brodell, is one of the most common compressive dressing following orthopedics surgery during the last 30 years, with the benefits of reducing tissue bleeding and edema by increasing intramuscular and intraarticular pressures [21]. However, Concerns about the complications such as peroneal nerve palsy, bruises and patient-reported discomforts still remain [6-8]. Due to the effective modern multi-modal swelling management, modified Robert Jones bandage use after total knee arthroplasty may now be unnecessary. To our best
Table 4 Comfort level at different time points

\begin{tabular}{llll}
\hline Comfort level & $\begin{array}{l}\text { Compression } \\
\text { group }\end{array}$ & $\begin{array}{l}\text { Control } \\
\text { group }\end{array}$ & $P$ value \\
\hline *Postoperative $24 \mathrm{~h}$ & 0 & 0 & 0.03 \\
Very comfortable & 2 & 4 & \\
Somewhat comfortable & 6 & 12 & \\
Fair & 27 & 24 & 0.58 \\
Somewhat uncomfortable & 9 & 4 & \\
Very uncomfortable & & & \\
*Postoperative $72 \mathrm{~h}$ & 1 & 1 & \\
Very comfortable & 7 & 8 & \\
Somewhat comfortable & 20 & 21 & \\
Fair & 13 & 13 & \\
Somewhat uncomfortable & 3 & 1 & \\
Very uncomfortable & ${ }^{*}$ P values calculated using the Mann-Whitney U test &
\end{tabular}

knowledge, the present study was the first to evaluate the effect of MRJB in an ERAS program after TKA without use of a tourniquet and post-operative drains.

In this study, we found significantly lower patient comfort level in the compression group during the first $24 \mathrm{~h}$, but no significant difference between the 2 groups at POD3, when MRJB had been removed for patients in the compression group. This was in accord with the previous study, compression therapy was with poor patients' compliance [4]. One of the reasons was reported to be the compression induced discomfort factors, including obliteration of circulation, "too hot" to wear, limb soreness, dermatitis or itching [22]. Moreover, low-pressure compression therapy was determined to be more comfortable than the high-pressure compression therapy [23].

Another finding of our study was that there was no difference in swelling, ROM and total blood loss between the 2 groups, and this was similar with a RCT performed by Pinsornsak et al. In their study, MRJB were placed for $24 \mathrm{~h}$ after TKA in the compression group, while patients in the control group received no compression but conventional wound dressing with sterile gauze pads only [6]. The difference between their study and ours was that they performed with routine tourniquet, no administration of intra-articular TXA or post-operative corticoids. In contrast, Charalambides et al. reported that compression bandage could control intra-articular bleeding effectively and few patients with compression bandaging experienced post-operative lower limb swelling [3]. However, the study was not in an enhanced recovery setup and the swelling was not evaluated by knee circumference. One of the possible reasons for the positive result of Charalambides et al.'s study may be the bandages were maintained for $48 \mathrm{~h}$, 
which was at twice the time of ours. And this may be too long for patients to achieve early mobilization and may be conflict to the idea of ERAS, as this bandage is bulky and hard for patients to do flexion exercise.

Furthermore, we found no differences in pain relief between the two groups. However, in a study evaluating the effect of compression bandage on pain control, Andersen et al. found patients with compression bandage experienced less pain than those with non-compression bandage [24]. This might be due to the cooling effect of cryotherapy in our study was partly affected by MRJB because of its thick layer [25], as cryotherapy was reported to reduce pain by slowing the conduction of nerve signals [26].

There are several limitations in our study. First, we did not measure the inflammatory markers before surgery, so the level of inflammation could be confounding issue and may have effect on knee swelling. However, the effect may be negligible due to the randomization design. Second, sub-bandage pressure measurement was not performed in each patient with the MRJB dressing, so the interface pressures might differ with each application. However, measurement of sub-bandage pressure is not practical and a pressure-guided application method of MRJB was not routinely used in clinical practice. Third, patients were not blinded in this study, as it was difficult to prevent patients from noticing if they received compression or not. Fourth, during our clinical practice, we found intraoperative tourniquet was still necessary for patients with severe obesity because of their greater surgical difficulty, so we excluded patients with a BMI > 35. Therefore, our conclusion may not be applicable for patients with severe obesity.

\section{Conclusions}

In conclusion, we found avoidance of MRJB use could provide higher patients' reported comfort level, without increasing swelling, blood loss, severity of pain or damaging knee function. Therefore, MRJB after primary TKA without tourniquet and drainage may not be routinely indicated in common clinical use.

\section{Abbreviations}

CT: Computed tomography; DVT: Deep venous thrombosis; MRJB: Modified Robert Jones bandage; PE: Pulmonary embolism; POD: Postoperative day; ROM: Range of motion; TKA: Total knee arthroplasty; VAS: Visual analog scale

\section{Acknowledgements}

This study adheres to CONSORT guidelines. We would like to thank the relevant staff for guidance and assistance for their support and collaboration in our hospital.

\section{Availability of data and materials}

The datasets used and/or analyzed during the current study are available from the corresponding author on reasonable request.

\section{Authors' contributions}

ZKZ, FXP conceived and designed this study; HDY, HYW XR and SYY collected the data; HDY, HYW performed the statistical analysis; HYW and HDY prepared Tables 1-4; HDY, KZ and HYW wrote the manuscript; HDY and ZKZ revised this manuscript. All authors reviewed the final manuscript. All authors agree to be accountable for all aspects of the work.

\section{Ethics approval and consent to participate}

This study was approved by the local institutional review board of West China Hospital, Sichuan University (No. 201302008). Written informed consent (including patients' details, images or videos) was obtained from all participants. The trial was registered in the Chinese Clinical Trial Registry (ChiCTR-INR-16010177) dated 18th December 2016. All experiments were performed in accordance with relevant guidelines and regulations. This study was conducted in accordance to the Declaration of Helsinki.

\section{Consent for publication}

Not applicable.

\section{Competing interests}

The authors declare that they have no competing interests.

\section{Publisher's Note}

Springer Nature remains neutral with regard to jurisdictional claims in published maps and institutional affiliations.

Received: 24 July 2018 Accepted: 25 September 2018

Published online: 05 October 2018

\section{References}

1. Carr AJ, Robertsson O, Graves S, Price AJ, Arden NK, Judge A, Beard DJ. Knee replacement. Lancet. 2012;379(9823):1331-40.

2. Holm B, Kristensen MT, Bencke J, Husted H, Kehlet H, Bandholm T. Loss of knee-extension strength is related to knee swelling after total knee arthroplasty. Arch Phys Med Rehabil. 2010;91(11):1770-6.

3. Charalambides C, Beer M, Melhuish J, Williams RJ, Cobb AG. Bandaging technique after knee replacement. Acta Orthop. 2005:76(1):89-94.

4. Ramelet AA. Compression therapy. Dermatol Surg. 2002;28(1):6-10.

5. Ogata K, Whiteside LA. Effects of external compression on blood flow to muscle and skin. Clin Orthop Relat Res. 1982;(168):105-7.

6. Pinsornsak P, Chumchuen S. Can a modified Robert Jones bandage after knee arthroplasty reduce blood loss? A prospective randomized controlled trial. Clin Orthop Relat Res. 2013;471(5):1677-81.

7. Idusuyi $\mathrm{OB}$, Morrey BF. Peroneal nerve palsy after total knee arthroplasty. Assessment of predisposing and prognostic factors. J Bone Joint Surg Am. 1996:78(2):177-84

8. Hughes DL, Crosby AC. Treatment of knee sprains: modified Robert Jones or elastic support bandage? J Accid Emerg Med. 1995:12(2):115-8.

9. Huang Z, Xie X, Li L, Huang Q, Ma J, Shen B, Kraus VB, Pei F. Intravenous and topical tranexamic acid alone are superior to tourniquet use for primary Total knee arthroplasty: a prospective, randomized controlled trial. J Bone Joint Surg Am. 2017;99(24):2053-61.

10. Rytter S, Stilling M, Munk S, Hansen TB. Methylprednisolone reduces pain and decreases knee swelling in the first $24 \mathrm{~h}$ after fast-track unicompartmental knee arthroplasty. Knee Surg Sports Traumatol Arthrosc. 2017;25(1):284-90

11. Richardson AB, Bala A, Wellman SS, Attarian DE, Bolognesi MP, Grant SA Perioperative dexamethasone administration does not increase the incidence of postoperative infection in Total hip and knee arthroplasty: a retrospective analysis. J Arthroplast. 2016;31(8):1784-7.

12. Han C, Kuang MJ, Ma JX, Ma XL. Is pregabalin effective and safe in total knee arthroplasty? A PRISMA-compliant meta-analysis of randomizedcontrolled trials. Medicine. 2017;96(26):e6947.

13. Onda A, Ogoshi A, Itoh M, Nakagawa T, Kimura M. Comparison of the effects of treatment with celecoxib, loxoprofen, and acetaminophen on postoperative acute pain after arthroscopic knee surgery: a randomized, parallel-group trial. J Orthop Science. 2016;21(2):172-7.

14. Nadler SB, Hidalgo $\mathrm{JH}$, Bloch T. Prediction of blood volume in normal human adults. Surgery. 1962:51(2):224-32.

15. Gross JB. Estimating allowable blood loss: corrected for dilution. Anesthesiology. 1983;58(3):277-80. 
16. Munk S, Jensen NJ, Andersen I, Kehlet H, Hansen TB. Effect of compression therapy on knee swelling and pain after total knee arthroplasty. Knee Surg Sports Traumatol Arthrosc. 2013;21(2):388-92.

17. Li B, Wen Y, Wu H, Qian Q, Lin X, Zhao H. The effect of tourniquet use on hidden blood loss in total knee arthroplasty. Int Orthop. 2009;33(5):1263-8.

18. Ishida K, Tsumura N, Kitagawa A, Hamamura S, Fukuda K, Dogaki Y, Kubo S, Matsumoto T, Matsushita T, Chin T, et al. Intra-articular injection of tranexamic acid reduces not only blood loss but also knee joint swelling after total knee arthroplasty. Int Orthop. 2011;35(11):1639-45.

19. Godier A, Roberts I, Hunt BJ. Tranexamic acid: less bleeding and less thrombosis? Crit Care. 2012;16(3):135

20. Yue C, Wei R, Liu Y. Perioperative systemic steroid for rapid recovery in total knee and hip arthroplasty: a systematic review and meta-analysis of randomized trials. J Orthop Surg Res. 2017;12(1):100.

21. Brodell JD, Axon DL, Evarts CM. The Robert Jones bandage. J Bone Joint Surg Bri. 1986;68(5):776-9.

22. Raju S, Hollis K, Neglen P. Use of compression stockings in chronic venous disease: patient compliance and efficacy. Ann Vasc Surg. 2007;21(6):790-5.

23. Ayhan $H$, Iyigun $E$, Ince $S$, Can MF, Hatipoglu S, Saglam M. A randomised clinical trial comparing the patient comfort and efficacy of three different graduated compression stockings in the prevention of postoperative deep vein thrombosis. J Clin Nurs. 2015;24(15-16):2247-57.

24. Andersen LO, Husted H, Otte KS, Kristensen BB, Kehlet H. A compression bandage improves local infiltration analgesia in total knee arthroplasty. Acta Orthop. 2008;79(6):806-11.

25. Weresh MJ, Bennett GL, Njus G. Analysis of cryotherapy penetration: a comparison of the plaster cast, synthetic cast, ace wrap dressing, and Robert-Jones dressing. Foot Ankle Int. 1996;17(1):37-40.

26. Algafly AA, George KP. The effect of cryotherapy on nerve conduction velocity, pain threshold and pain tolerance. Br J Sports Med. 2007;41(6):3659 discussion 369

Ready to submit your research? Choose BMC and benefit from:

- fast, convenient online submission

- thorough peer review by experienced researchers in your field

- rapid publication on acceptance

- support for research data, including large and complex data types

- gold Open Access which fosters wider collaboration and increased citations

- maximum visibility for your research: over $100 \mathrm{M}$ website views per year

At $\mathrm{BMC}$, research is always in progress.

Learn more biomedcentral.com/submissions 